\title{
Cecocentral scotoma as the initial manifestation of subacute bacterial endocarditis
}

This article was published in the following Dove Press journal:

Clinical Ophthalmology

28 February 201I

Number of times this article has been viewed

\section{Danielle Savitsky Strauss \\ Samuel Baharestani \\ Julia Nemiroff \\ Kiran Amesur \\ David Howard}

New York University Langone Medical Center, New York, NY, USA
Correspondence: Danielle Strauss NYU Department of Ophthalmology, 462 First Avenue, 5N 16 New York, NY I00I6, USA

Tel +I (2I2) 2636434

Fax +I (2I2) 2638749

Email danielle.strauss@nyumc.org
Introduction: We report a case of a 67-year-old male who presented with a cecocentral scotoma caused by a septic embolus from subacute bacterial endocarditis (SBE).

Methods: A 67-year-old man presented with sudden, painless decreased vision in the left eye. A dilated fundoscopic exam, Humphrey visual field test, transthoracic echocardiogram, abdominal computed tomography (CT), and blood cultures were all performed.

Results: A dilated fundoscopic exam revealed temporal segmental optic disc pallor on the left, and Humphrey visual field testing demonstrated a dense left cecocentral scotoma. When the patient developed fever $\left(103.9^{\circ} \mathrm{F}\right)$ and palpitations, transthoracic echocardiogram revealed valvular vegetations, and contrast $\mathrm{CT}$ of the abdomen revealed an abscess in the dome of the liver likely due to an infectious thrombus. Blood cultures grew viridians group streptococci in three separate peripheral collections.

Conclusion: This case illustrates that a sudden cecocentral scotoma may be the initial manifestation of SBE.

Keywords: endocarditis, scotoma, streptococcal infections, visual fields

\section{Introduction}

Subacute bacterial endocarditis (SBE) is an indolent microbial infection of the endocardium with the potential for systemic dissemination by way of septic emboli. We report the case of a 67-year-old male who presented with a cecocentral scotoma caused by an infectious embolus from SBE.

\section{Case report}

A 67-year-old man presented to our emergency department (ED) complaining of sudden, painless decreased vision in the left eye for 3 days. He reported no other systemic or ocular symptoms, including no fever, weight loss, pain on chewing, joint pain, or skin rashes. Other than treatment for dental caries 1 week prior to presentation, he had not sought medical attention for over 10 years. On examination, his visual acuity was 20/20 on the right and count fingers on the left. Extraocular movements were full bilaterally. Pupillary examination revealed a $2+$ afferent pupillary defect on the left. The patient correctly identified nine of nine Ishihara color plates on the right but only four of nine color plates on the left. Anterior segment examination was otherwise within normal limits, as were the intraocular pressures. Dilated fundoscopic exam revealed sharp, nonedematous, nonglaucomatous-appearing optic disks bilaterally but with temporal segmental pallor on the left. The remainder of the peripheral posterior exam was within normal limits, including no Roth or cotton wool spots, 
no Hollenhorst plaques, no retinal edema or hemorrhage, and no neovascularization. Other than a mildly elevated temperature to $100.1^{\circ} \mathrm{F}$, all other vital signs were within normal limits, and there were no focal neurologic findings. Laboratory testing revealed a sedimentation rate of 80 and a white blood cell count of $11,000 / \mu \mathrm{L}$ with $78 \%$ neutrophils. Platelet count was $225,000 / \mu \mathrm{L}$, and the hematocrit and basic metabolic panel were within normal limits.

As computed tomography (CT) and/or magnetic resonance imaging (MRI) were not acutely available, we performed Humphrey visual field testing, which demonstrated a dense left cecocentral scotoma (Figure 1). The differential diagnosis of a pale nerve with a cecocentral scotoma includes an embolic event, optic neuritis, toxic optic neuropathy, and nutritional deficiency. The patient was admitted to the intensive care unit for further medical workup, including further imaging and blood studies. However, he left the hospital against medical advice within 1 day of admission. Seventy-two hours later, the patient returned to the ED with increased temperature $\left(103.9^{\circ} \mathrm{F}\right)$, palpitations, and stable decreased visual acuity of the left eye and was therefore readmitted. Transthoracic echocardiogram revealed valvular vegetations (not shown), and contrast CT of the abdomen revealed an abscess in the dome of the liver that was likely due to an infectious thrombus (Figure 2). Chest X-ray and CT of the head showed no focal lesions. The patient's blood cultures grew Streptococcus viridans in three separate peripheral collections. Following intravenous antibiotic treatment, his systemic condition steadily improved over 1 week, warranting discharge from the hospital. However, his visual acuity and field deficits remained unchanged. The patient continued oral antibiotic therapy for 3 additional

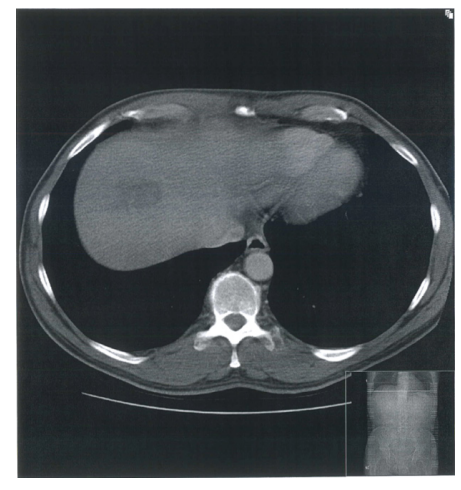

Figure 2 Computed tomography scan of the abdomen with contrast showing an abscess in the dome of the liver.

weeks until repeat blood cultures showed no evidence of residual infection.

On serial yearly follow-up examinations almost a decade after the original insult, the patient's low vision status on the left persists with decreased Snellen vision, reproducible red desaturation, and decreased color plates on that side. Yearly follow-up Humphrey visual field testing has remained unchanged. Follow-up intravenous fluoroscein angiography has remained unremarkable, with recent fundus photos of the left eye (Figure 3) showing inferotemporal disk pallor. Follow-up MRI was not acquired, as the patient's examination and visual defect remained stable over many years. We postulate that an infectious embolus from endocarditis impeded circulation, causing ischemia and segmental infarction of the left optic nerve and affecting the maculopapillary bundle.

\section{Discussion}

We report the first case of a cecocentral scotoma presenting as the initial manifestation of SBE. It is important for both

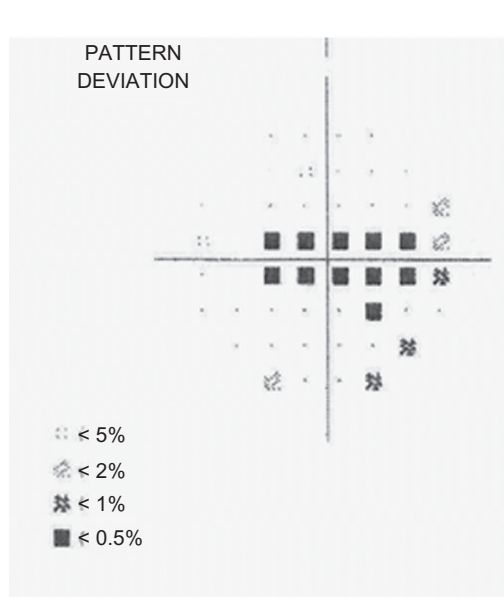

Figure I Humphrey visual field testing showing a dense left cecocentral scotoma.

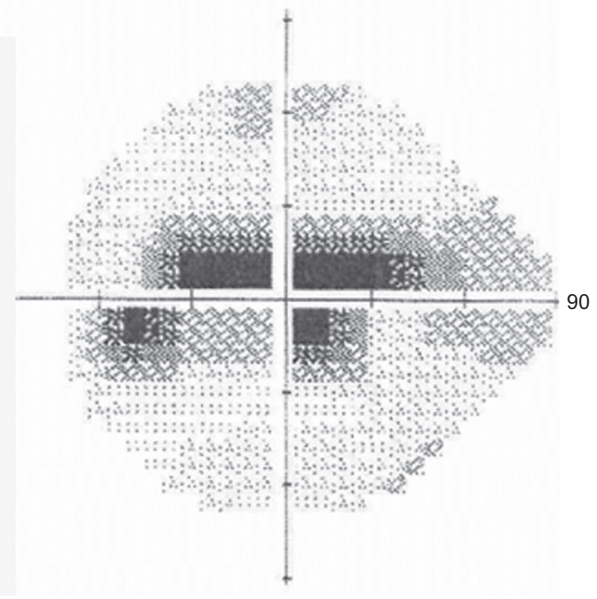




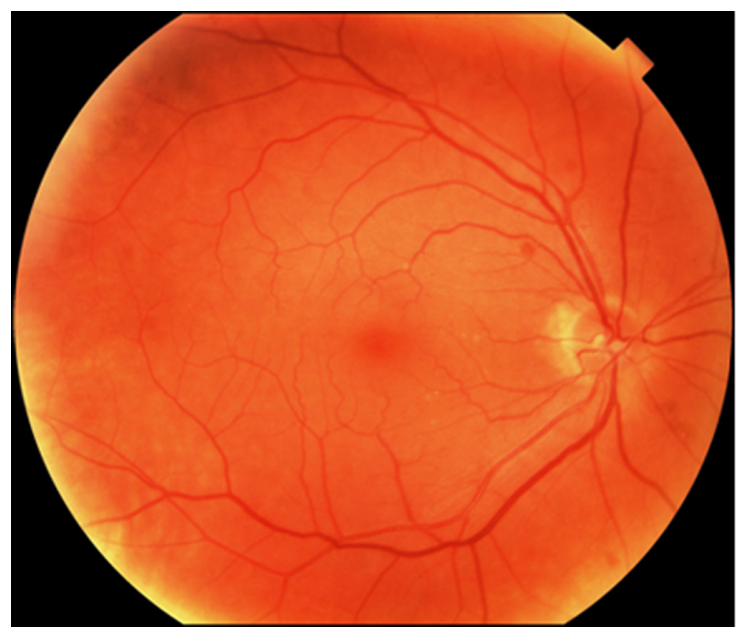

Figure 3 Fundus photo showing inferotemporal disc pallor in the left eye.

the ophthalmologist and general practitioner to recognize that infective endocarditis has varied presentations, ranging from general malaise to loss of appetite. If left untreated, it can be fatal. ${ }^{1}$ It is commonly caused by relatively avirulent viridans streptococci organisms that have a propensity to adhere to damaged heart valves and endothelium. ${ }^{2}$ Infective endocarditis is typically handled on an inpatient basis to employ the use of intravenous bacteriocidal antibiotics tailored to the specific organism found in cultures and also to closely monitor the patient. ${ }^{3}$ Another option is to administer antibiotics on an outpatient basis but only after treatment has already been started in the hospital and a full initial assessment performed. ${ }^{1}$

An embolic event due to SBE is a frequent and potentially life-threatening complication of the disease. It has been reported that neurological complications due to embolic events may be as high as $20 \%-40 \% .^{3}$ MRI may show infarctions scattered throughout the brain secondary to emboli. Ocular manifestations of embolic disease can include Roth spots, retinal hemorrhages, and infectious vitritis. ${ }^{3}$ Because SBE often presents as a fever of unknown origin, ophthalmic signs of the disease may often present prior to a confirmatory echocardiogram or blood culture but are often visually insignificant. Some studies have demonstrated premacular hemorrhage as the first sign of SBE, whereas others have reported patients with seizures, headaches, and Roth spots prior to being diagnosed with SBE. ${ }^{4,5,6}$

Systemic embolization of infective thrombi reportedly occurs in $45 \%-65 \%$ cases of SBE. ${ }^{7}$ We postulate that visual symptoms and signs occur from turbulent flow within the small vascular channels supplying the optic nerve head, causing local ischemia and thereby leading to infarction of

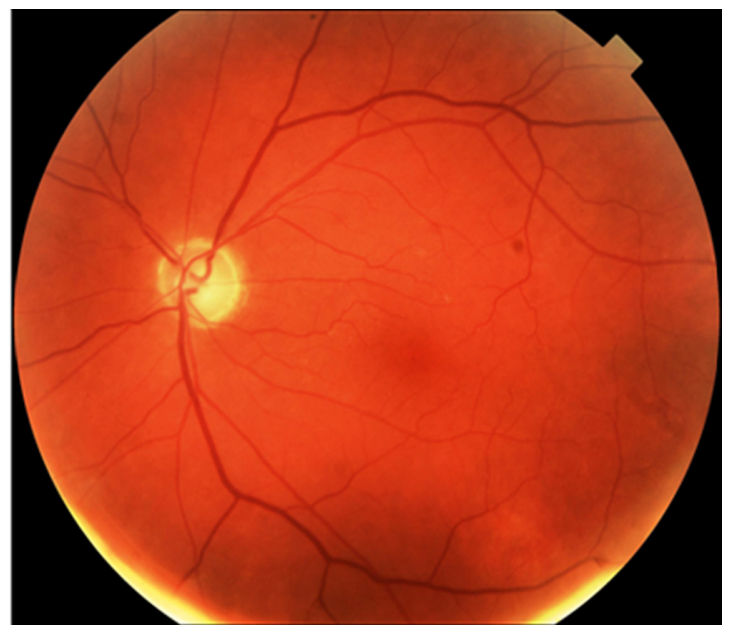

the retinal nerve fiber layer. The standard of practice is to rely on echocardiograms as a diagnostic and prognostic tool to guide our management of SBE; however, our ability to predict the risk of embolic events is limited. ${ }^{8}$

In our case, the sudden appearance of a cecocentral scotoma in the absence of systemic symptoms and grossly abnormal laboratory values was the harbinger of future embolic events in this patient and the first manifestation of a serious generalized infectious process. Our case confirms that ophthalmic events may indeed herald SBE and that ophthalmologists should consider systemic workup (in concert with primary care physicians) for patients who present with sudden cecocentral scotomas or other visual field defects.

\section{Disclosure}

There were no conflicts of interest or financial interests for any of the authors of this manuscript. The authors have no commercial or proprietary interest in any of the material discussed in the article. There were no grants in support of this article.

\section{References}

1. Connaughton M, Rivett J. Easily missed? Infective endocarditis. BMJ. 2010;341:267-268.

2. Cunha BA, D'Elia AA, Pawar N, Schoch P. Viridens streptococcal (Streptococcus intermedius) mitral valve subacute bacterial endocarditis (SBE) in a patient with mitral valve prolapsed after a dental procedure: the importance of antibiotic prophylaxis. Heart Lung. 2010;1:64-72.

3. The Task Force on the Prevention, Diagnosis, and Treatment of Infective Endocarditis of the European Society of Cardiology (ESC). Guidelines on the prevention, diagnosis, and treatment of infective endocarditis (new version 2009). http://www.escardio.org/guidelines-surveys/ esc-guidelines/GuidelinesDocuments/guidelines-IE-FT.pdf. Accessed January 18, 2011 
4. Seles S, Lang GE. [Ocular manifestations of an infectious endocarditis]. Klin Monbl Augenheilkd. 2007;7:606-608.

5. Kim JE, Han DP. Premacular hemorrhage as a sign of subacute bacterial endocarditis. Am J Ophthalmol. 1995;2:250-251.

6. Varadarjan J, Eggenberger ER. Infective endocarditis: a photo essay. J Neuroophthalmol. 1996;4:291-294.
7. Khan F, Khakoo R, Failinger C. Managing embolic myocardial infarction in infective endocarditis: current options. J Infect. 2005;3:101-105.

8. Habib G. Embolic risk in subacute bacterial endocarditis: determinants and role of transesophageal echocardiography. Curr Cardiol Rep. 2003;2: 129-136.

\section{Publish your work in this journal}

Clinical Ophthalmology is an international, peer-reviewed journal covering all subspecialties within ophthalmology. Key topics include: Optometry; Visual science; Pharmacology and drug therapy in eye diseases; Basic Sciences; Primary and Secondary eye care; Patient Safety and Quality of Care Improvements. This journal is indexed on

\section{Dovepress}

PubMed Central and CAS, and is the official journal of The Society of Clinical Ophthalmology (SCO). The manuscript management system is completely online and includes a very quick and fair peer-review system, which is all easy to use. Visit http://www.dovepress.com/ testimonials.php to read real quotes from published authors. 